Relato de CAso

CASE REPORT

\title{
Hipoparatireoidismo Primário Manifestando-se com Aumento de Enzimas Musculares ${ }^{(*)}$
}

\section{Primary Hypoparathyreoidism with Raised Muscle Enzymes}

\author{
Simone Appenzeller ${ }^{(1)}$, Gláucio W. R. Castro ${ }^{(2)}$, Sandra Regina Fernandes ${ }^{(3)}$, \\ Adil M. Samara ${ }^{(4)}$, Manoel B. Bértolo(5)
}

\section{RESUMO}

Os autores relatam o caso de um jovem de 18 anos de idade com fraqueza muscular generalizada, cãibras e crises convulsivas, tratado com corticosteróides por oito anos em decorrência de um diagnóstico de polimiosite, sem melhora clínica. Ao exame físico apresentava força muscular normal, ausência de atrofias musculares, diminuição de reflexos tendíneos profundos e presença do sinal de Chvostek e Trousseau. A hipótese diagnóstica inicial foi de miopatia metabólica e a investigação laboratorial revelou cálcio sérico e urinário diminuídos e dosagem de paratormônio (PTH) indetectável. O diagnóstico final foi de hipoparatireoidismo, tendo sido o paciente tratado com cálcio endovenoso. A tomografia de crânio demonstrou calcificações difusas, características da síndrome de Fahr. O paciente recebeu alta assintomático com carbonato de cálcio e colecalciferol.

Palavras-chave: hipoparatireoidismo, miopatia metabólica, síndrome de Fahr.

\section{INTRODUÇÃO}

A presença de fraqueza muscular com aumento de enzimas musculares sugere o diagnóstico de miopatia ${ }^{(1,2)}$. A investigação de um paciente que apresenta fraqueza muscular inclui hormônios tireoidianos, enzimas musculares e hepáticas, cálcio sérico e urinário. Muitas vezes a história nos fornece indícios quanto ao diagnóstico mais provável. Fraqueza muscular com atrofia muscular sugere o diagnóstico

\begin{abstract}
The authors report a case of an 18-year-old boy using prednisone for eight years for a misdiagnosis of polymyositis. His complains were diffuse weakness, cramps and seizures, with progressive worsening and with no improvement despite treatment with corticosteroid. On admission, the physical examination didn't show muscular weakness or atrophy. Deep tendom reflexes were absent and Chvostek and Trousseau signs were found. The diagnosis of a metabolic myopathy was considered and further laboratory findings revealed a low serum and urinary calcium, undetectable PTH. The diagnosis of hypoparathyreoidism was made and the patient was treated with endovenous calcium. Cranial tomography revealed diffuse calcifications, suggestive of Fahr's syndrome. The patient recovered completely and was discharged with oral calcium carbonate and colecalciferol.
\end{abstract}

Keywords: hypoparathyreoidism, metabolic miopathy, Fahr's syndrome.

de miopatia inflamatória. A presença de sinais e sintomas de involução do desenvolvimento neurológico sugere distrofia muscular. Por outro lado, a presença de cãibras e crises convulsivas dão indícios da presença de alterações eletrolíticas, em especial, a hipocalcemia sintomática ${ }^{(2)}$.

Os autores relatam um caso de hipoparatireoidismo idiopático, com fraqueza muscular e aumento de enzimas musculares.

\footnotetext{
* Trabalho realizado na Faculdade de Ciências Médicas da Universidade Estadual de Campinas (FCM/Unicamp), Campinas, SP, Brasil. Recebido em 24/1 1/2003. Aprovado, após revisão, em 06/04/2005.

1. Pós-graduanda da FCM/Unicamp.

2. Ex residente da Disciplina de Reumatologia da FCM/Unicamp.

3. Professora doutora da Disciplina de Reumatologia da FCM/Unicamp.

4. Professor titular e chefe da Disciplina de Reumatologia da FCM/Unicamp.

5. Professor doutor e chefe do Departamento de Clínica Médica da FCM/Unicamp.

Endereço para correspondência: Dra. Simone Appenzeller. Faculdade de Ciências Médicas da Universidade Estadual de Campinas (FCM/Unicamp), Rua Zeferino Vaz, s/n, CEP 13081-230. Campinas, SP, Brasil. E-mail: appenzel@unicamp.br
} 


\section{RELATO DE CASO}

Paciente de 18 anos de idade, masculino, caucasóide, natural e procedente de Rondônia, Brasil, foi encaminhado a nosso serviço com diagnóstico de polimiosite refratária a corticoterapia. O paciente queixava-se de fraqueza muscular generalizada, com leve predomínio em regiões proximais do tronco há oito anos. Referia cãibras freqüentes, principalmente nos membros superiores e inferiores e crises convulsivas parciais diárias sem aura no último ano.

Nos últimos oito anos usou prednisona em doses variáveis, sem nunca apresentar melhora clínica e atualmente estava em uso de $60 \mathrm{mg} /$ dia de prednisona e de anticonvulsivantes (fenitoína $100 \mathrm{mg}$ ), sem controle adequado das crises. A mãe referia bom desenvolvimento neuropsicomotor na infância e adolescência. Evolui há dois anos com dificuldade de concentração e de aprendizado.

Ao exame físico, peso de $54 \mathrm{~kg}$, altura $172 \mathrm{~cm}$, com índice de massa corporal de $18,25 \mathrm{~kg} / \mathrm{m}^{2}$. Apresentava atraso no desenvolvimento puberal para a idade, com ausência de pilificação característica nos membros e na face. Dentição decídua, com exceção dos incisivos superiores e inferiores. Pressão arterial de 120/72 mmHg no membro superior direito, freqüência cardíaca de $74 \mathrm{bpm}$, freqüência respiratória de 14 incursões por minuto. A ausculta cardíaca e a respiratória estavam dentro dos padrões de normalidade. A palpação abdominal estava normal. Ao exame osteomuscular apresentava-se eutrófico, com força muscular grau $\mathrm{V}$ nos membros superiores e inferiores. Não apresentava alteração no exame osteomuscular ativo e também não referia dor durante as manobras ativas e passivas. Os reflexos osteotendíneos estavam abolidos bilateralmente nos membros superiores e inferiores, a coordenação motora estava preservada e normal.

Os resultados dos exames solicitados relevaram um aumento de creatina quinase, diminuição do cálcio e aumento de fósforo sérico com paratormônio (PTH) indetectável (Tabela 1).

As radiografias de ossos longos demonstravam ossos levemente arqueados e osteopênicos. A tomografia do crânio, realizada para investigação de crises convulsivas, demonstrou calcificações de núcleos da base, tálamo, núcleos denteados bilateralmente, além de calcificações subcorticais envolvendo lobos cerebrais.

Foi estabelecido o diagnóstico de hipoparatireoidismo idiopático e síndrome de Fahr. Em razão da baixa concentração sérica de cálcio e da sintomatologia importante do paciente, com crises convulsivas freqüentes, ele foi inicialmente tratado com cálcio endovenoso até a normalização sérica e depois com colecalciferol (6.000.000 UI/dia) e cálcio $1 \mathrm{~g} / \mathrm{dia}$. O paciente apresentou acentuada melhora, mantendo-se assintomático pelo período de seguimento de cinco meses com normalização de enzimas musculares e níveis séricos de cálcio.

TABELA 1

RESULTADOS DE EXAMES LABORATORIAIS

\begin{tabular}{|c|c|}
\hline Exame laboratorial & $\begin{array}{l}\text { Resultado } \\
\text { (valor da normalidade do serviço) }\end{array}$ \\
\hline $\begin{array}{l}\text { Cálcio sérico }(\mathrm{mg} / \mathrm{dl}) \\
\text { Cálcio em urina } \\
24 \text { horas }(\mathrm{mg} / 24 \mathrm{~h}) \\
\text { Magnésio sérico }(\mathrm{mg} / \mathrm{dl})\end{array}$ & $\begin{array}{l}4,7(8,6-10) \\
1,5(100-300)\end{array}$ \\
\hline $\begin{array}{l}\text { CK }(U / L) \\
\text { CKMB }(U / L)\end{array}$ & $\begin{array}{l}818 \text { (até 212) } \\
32 \text { (até 10) }\end{array}$ \\
\hline Potássio sérico (mEq/l) & $2,3(3,5-5,5)$ \\
\hline $\begin{array}{l}\text { AST }(\mathrm{U} / \mathrm{L}) \\
\text { ALT }(\mathrm{U} / \mathrm{L}) \\
\text { Fosfatase alcalina }(\mathrm{U} / \mathrm{L}) \\
\text { Gama GT U/L) }\end{array}$ & $\begin{array}{l}20 \text { (até 37) } \\
33 \text { (até 40) } \\
167 \text { (até 269) } \\
78 \text { (até 40) }\end{array}$ \\
\hline $\begin{array}{l}\text { Fósforo sérico (mg/dl) } \\
\text { Fósforo urinário (mg/24h) }\end{array}$ & $\begin{array}{l}8(2,7-4,5) \\
32,30(0,4-1,3)\end{array}$ \\
\hline $\begin{array}{l}\text { Uréia }(\mathrm{mg} / \mathrm{dl}) \\
\text { Creatinina (mg/dl) }\end{array}$ & $\begin{array}{l}15 \text { (até 49) } \\
0,84 \text { (até 1,2) }\end{array}$ \\
\hline Paratormônio (Pg/ml) & $<1(7-57)$ \\
\hline Amilase $(\mathrm{U} / \mathrm{L})$ & 82 (até 34) \\
\hline $\begin{array}{l}\text { TSH (uUI/ml) } \\
\text { T4 livre (ug/dl) }\end{array}$ & $\begin{array}{l}1,2(0,35-4,1) \\
1,1(0,9-1,8)\end{array}$ \\
\hline Albumina sérica $(\mathrm{g} / \mathrm{dl})$ & $4(3,5-5,0)$ \\
\hline
\end{tabular}

\section{DISCUSSÃO}

A fraqueza muscular é um sinal importante de pacientes encaminhados para investigação de miopatias ${ }^{(1,2)}$. Além da mensuração da força muscular, outros sinais e sintomas são importantes para o diagnóstico diferencial das fraquezas musculares.

As miopatias inflamatórias cursam, após algum tempo, com atrofias musculares generalizadas. Ao exame físico do paciente atrofia muscular não foi detectável, o que fez sugerir o diagnóstico de uma miopatia de origem metabólica. A presença de cãibras e de espasmo dos músculos do carpo (Sinal de Trousseau) e dos músculos faciais durante a digito-percussão (sinal de Chvostek) sugerem a presença de hipocalcemia sintomática, ou seja, favorecem o diagnóstico de uma miopatia metabólica ${ }^{(1,2)}$. 
O aumento de enzimas musculares é um achado raro no hipoparatireoidismo ${ }^{(3-5)}$. Em alguns relatos os níveis de creatino quinase (CK) variam inversamente com as concentrações séricas de cálcio ${ }^{(6-8)}$. O aumento de CK foi atribuído à presença de tetania, porém, pode também ocorrer na sua ausência ${ }^{(2,7)}$. O mecanismo mais provavelmente associado ao aumento do CK deve ser um aumento na permeabilidade da membrana muscular induzida pela hipocalcemia ${ }^{(2,9)}$. Em estudos prévios, a biópsia muscular em pacientes com hipoparatireoidismo revela achados inespecíficos, mas ausência de infiltrado inflamatório e regeneração de fibras musculares $^{(2,10)}$. Infelizmente, não foi realizada biópsia muscular no presente caso.

Os sinais e sintomas mais proeminentes da hipocalcemia dependem da forma de instalação e do tempo da hipocalcemia $^{(1)}$. O aumento da excitabilidade neuromuscular é a manifestação clínica mais freqüente. Parestesias nas mãos e nos pés ocorrem nos casos mais leves. Quando a diminuição do cálcio iônico se torna mais expressiva, cãibras musculares e convulsões podem ocorrer, como o observado em nosso paciente. Os sinais da tetania latente consistem no sinal de Chvostek e Trousseau ${ }^{(1)}$. A arreflexia, observada neste paciente, também é secundária à hipocalcemia, visto que o cálcio é necessário para a condução do estímulo nervoso.

A idade de início da hipocalcemia pode ser determinada pelas alterações dentárias. $\mathrm{O}$ atraso na erupção dentária, como observado neste paciente, sugere um início na infância.

Vários distúrbios mentais têm sido associados à hipocalcemia, em especial a irritabilidade, a depressão e a psicose ${ }^{(1)}$. A hipocalcemia de longa data cursa com calcificações intracranianas, como observado neste paciente e denominada síndrome de Fahr, podendo acarretar hipogonadismo por deficiência de secreção de LH e FSH ${ }^{(1,11-13)}$.

Deformidades ósseas ocorrem durante a hipocalcemia prolongada no período de crescimento, quando a mineralização da matriz óssea é insuficiente, tornando o osso formado mais susceptível a deformidades e fraturas ${ }^{(1)}$.

Hipocalcemia ocorre quando há uma diminuição do cálcio ionizado, íon que afeta as funções neuromusculares, dentre outras. Uma diminuição do cálcio sérico total, como a que pode ocorrer em pacientes com hipoalbuminemia, não reflete, necessariamente, uma diminuição do cálcio ionizado ${ }^{(1)}$. Neste caso, observamos uma diminuição significativa do cálcio sérico com nível sérico de albumina normal, sugerindo indiretamente a presença também de uma diminuição do cálcio ionizado.

A concentração sérica normal de cálcio ionizado é mantida pelas ações diretas do PTH sobre os rins e o osso, bem como pelas ações indiretas, por meio da 1,25 (OH)2D, no intestino. No hipoparatireoidismo, verifica-se a redução da mobilização do cálcio do osso, diminuição de fosfatúria e formação reduzida de 1,25 (OH)2D, com conseqüente redução da absorção intestinal de cálcio. O resultado final da diminuição de secreção de PTH, como observado neste caso, é a hipocalcemia com albumina normal e hiperfosfatemia. A hipocalcemia e hiperfosfatemia com função renal normal são patognomônicas do hipoparatireoidismo, cujo diagnóstico é confirmado pelos níveis baixos ou indetectáveis de $\mathrm{PTH}^{(1)}$.

Os distúrbios hipocalcêmicos podem ser divididos, de acordo com a sua patogenia, em hipoparatireoidismo primário, em que a hipocalcemia se deve a secreção e/ou ação deficiente do PTH e hipocalcemia decorrente da disfunção do órgão-alvo, como em síndromes de má-absorção, insuficiência renal e deficiência de vitamina D. Neste último caso, a hipocalcemia é acompanhada de um aumento de PTH e com níveis séricos de fósforo normais ou discretamente diminuídos ${ }^{(1)}$. Em nosso caso, como observamos uma hipocalcemia, hiperfosfatemia e um PTH indetectável, a hipótese diagnóstica de hipoparatireoidismo foi considerada mais provável. O hipoparatireoidismo primário pode ser subdividido em três grandes grupos (Tabela 2).

O tratamento da hipocalcemia sintomática exige infusão endovenosa de cálcio, até o desaparecimento dos sintomas. $\mathrm{O}$ tratamento permanente consiste no uso de vitamina D e cálcio oral. O tratamento objetiva a menor concentração sérica de cálcio compatível com o desaparecimento dos sintomas, visto que, sem o PTH, a excreção urinária de cálcio aumenta e conseqüentemente aumenta a possibilidade de nefrolitíase.

Este relato de caso demonstra de forma clara que a história e o exame físico do paciente são importantes para o diagnóstico diferencial de fraqueza muscular. $\mathrm{Na}$ ausência de história de fraqueza proximal e de atrofia muscular, outras causas de miopatias devem ser pesquisadas. O hipoparatireoidismo é raro, mas um diagnóstico diferencial importante, principalmente na presença de cãibras e crises convulsivas.

TABELA 2

CAUSAS DE HIPOPARATIREOIDISMO

\begin{tabular}{ll}
\hline $\begin{array}{l}\text { Deficiência da secreção de } \\
\text { hormônios paratireoidianos }\end{array}$ & $\begin{array}{l}\text { Idiopático } \\
\text { Mutação do gene PTH } \\
\text { Cirúrgico } \\
\text { Infiltrativo }\end{array}$ \\
Resistência hormonal & $\begin{array}{l}\text { Pseudo-hipoparatireoidismo } \\
\text { tipo Ia e Ib }\end{array}$ \\
Funcional & $\begin{array}{l}\text { Hipomagnesemia } \\
\text { Pós-operatório }\end{array}$ \\
\hline
\end{tabular}




\section{REFERÊNCIAS}

1. Marx SJ: Hyperparathyroid and hypoparathyroid disorders. N Engl J Med 21; 343: 1863-75, 2000.

2. Barber J, Butler RC, Davie MW, Sewry CA: Hypoparathyroidism presenting as myopathy with raised creatine kinase. Rheumatology (Oxford) 40: 1417-8, 2001.

3. Hower J, Stuck H, Tackmann W, Stolecke H. CPK activity in hypoparathyroidism. N Engl J Med 287: 1098, 1972.

4. Battistella PA, Pozzan GB, Rigon F, Zancan L, Zaccelloo F: Autoimmune hypoparathyroidism and hyper-CK-aemia. Brain Dev 13: 61, 1991.

5. Van Offel JF, De Gendt CM, De Clerck LS, Stevens WJ: High bone mass and hypocalcaemic myopathy in a patient with idiopathic hypoparathyroidism. Clin Rheumatol 19: 64-6, 2000.

6. Ishikawa T, Inagaki H, Kanayama M, Manzai T: Hypocalcaemic hyper-CK-aemia in hypoparathyrodism. Brain Dev 12: 249-52, 1991.
7. Shane E, McClane KA, Olarte MR, Bilezikian JP: Hypoparathyroidism and elevated muscle enzymes. Neurology 3: 192-5, 1980.

8. Akmal M: Rhabdomyolysis in a patient with hypocalcaemia due to hypoparathyroidism. Am J Nephrol 13: 61-3, 1993.

9. Ishikawa T, Kanayama M, Oba T, Horie T: Hypocalcemic induced increase in creatine kinase in rats. Pediatr Neurol 18: 326-30, 1980.

10. Yamaguchi H, Okamoto K, Shooji M, Morimatsu M, Hirai S: Muscle histology of hypocalcaemic myopathy in hypoparathyroidism. J Neurol Neurosurg Psychiatry 50: 817-8, 1987.

11. Avrahami E, Cohn DF, Feibel M, Tadmor R: MRI demonstration and CT correlation of the brain in patients with idiopathic intracerebral calcification. J Neurol 241: 381-4, 1994.

12. Vega MG, Sousa AA, Lucca Junior F, Purich S, Tenassi ML: Extrapyramidal syndrome and hypoparathyroidism. On the identity of Fahr disease. Arq Neuropsiquiatr 52: 419-26, 1994.

13. Zafeiriou DI, Athanasiou M, Katzos G, Economou M, Kontopoulos E: Hypoparathyroidism and intracranial calcifications in betathalassemia major. J Pediatr 138: 411, 2001. 